\title{
The Current State of Subjective Training Load Monitoring-a Practical Perspective and Call to Action
}

\author{
Joseph O. C. Coyne ${ }^{1 *}$, G. Gregory Haff ${ }^{1}$, Aaron J. Coutts ${ }^{2}$, Robert U. Newton ${ }^{1}$ and Sophia Nimphius ${ }^{1}$
}

\begin{abstract}
This commentary delivers a practical perspective on the current state of subjective training load (TL) monitoring, and in particular sessional ratings of perceived exertion, for performance enhancement and injury prevention. Subjective measures may be able to reflect mental fatigue, effort, stress, and motivation. These factors appear to be important moderators of the relationship TL has with performance and injury, and they also seem to differ between open and closed skill sports. As such, mental factors may affect the interaction between TL, performance, and injury in different sports. Further, modeling these interactions may be limited due to the assumption that an independent signal can adequately account for the performance or injury outcomes. An independent signal model does not accurately reflect training environments where multiple stressors (e.g., mechanical, emotional, nutritional) impact adaptations. Common issues with using subjective TL monitoring, including a lack of differentiation between biomechanical, physiological, and cognitive load, may be overcome by considering psychometric measurement best practices, finer graded scales, and differential ratings of perceived exertion. Methods of calculating $T L$, including different acute and chronic time periods, may also need to be individualized to different sports and potentially different individuals within the same sport. As TL monitoring is predominately a "chronic" decisionmaking tool, "acute" decision-making tools, e.g., subjective wellness and autonomic nervous system measures, should be combined in a bespoke multivariate model to aid sports coaches. A call to action is presented for future research on key issues associated with $T L$ monitoring that will have relevance for practitioners in an applied setting.
\end{abstract}

\section{Key points}

- Subjective measures of training load may be able to reflect mental load, which appears to be an important moderator of training load's relationship with performance and injury.

- The relationship between training load, performance, and injury may differ between open and closed skill sports due to mental load.

- Subjective measures of training load are recommended in bespoke multi-factorial models assessing the relationship between training load, injury, and performance.

\footnotetext{
* Correspondence: coach@josephcoyne.com

${ }^{1}$ Centre for Exercise and Sports Science, School of Medical and Health

Sciences, Edith Cowan University, Joondalup, Western Australia, Australia

Full list of author information is available at the end of the article
}

- Future developments in training load monitoring should include quantifying the relationship between subjective measures, performance, and injury and establish preferred training load model calculations.

\begin{abstract}
Introduction
Training load monitoring is typically an attempt to quantify two interrelated relationships: the training load-performance relationship (TL-P) and training load-injury relationship (TL-I) [1]. Both of these relationships appear to be quadratic whereby if too much or too little training is completed, there is a higher likelihood of not performing well or becoming injured/ill $[1$, $2]$. There are two general TL constructs: internal and external. These constructs, along with their interaction,
\end{abstract}


have been described previously [1-4]. In practice, methods of monitoring TL vary considerably depending on the type of sport or activity [3]; however, TL models are commonly analyzed using training impulse, which is normally a product of an intensity factor and volume/ duration factor $[2,5]$.

Subjective measures of TL, and in particular, sessional ratings of perceived exertion (sRPE), are recommended as a primary measure of TL in systematic reviews of the literature [6,7]. Subjective measures may also be more sensitive and consistent than objective measures $[8,9]$, and SRPE has been reported as the most commonly assessed TL variable in most sports [10]. Besides sRPE, there are other subjective methods of assessing an athlete's response to training, e.g., visual analogue scales [9] and perceived wellness/stress questionnaires [11]. Although these measures will be highlighted later in the commentary, they are not usually incorporated into common TL models using training impulse as intensity factors. Due to the above factors, sRPE will be the principal focus of this commentary.

A basic model of an athlete's response to training can be estimated from data collected as part of the TL monitoring process $[1,5]$. Specifically, the difference between "fitness" (positive) and "fatigue" (negative) functions can be quantified with internal or external TL variables as training impulse $[1,5]$. The genesis of this basic TL model stems from the work of Bannister [5]. A recent simplified extension of this work has been the development of the acute to chronic workload ratio (ACWR) [12-14]. TL monitoring and in particular the ACWR has been readily adopted (especially in open skill sports) to inform training practices to minimize the likelihood of injury [1]. The ACWR has also been used as a tool to systematically progress injured athletes' rehabilitation and to quantify acceptable levels of injury risk prior to an athlete returning to competition $[14,15]$. The research on the ACWR suggests values above or below $\sim 0.8-1.3$ are associated with an increased risk of injury [12-14]. However, the level of evidence for this recommendation is not yet well developed and it is typically not advocated that practitioners completely avoid ranges outside $\sim 0.8-1.3$. These ranges may be practically impossible or undesired in certain situations like early rehabilitation and tapering. Practitioners should instead be cognizant that a higher injury risk may be present and combine this with other factors to make decisions.

Despite the association with injury risk, TL monitoring and ACWR currently appear to be poor predictors of injury $[2,16]$. This poor predictive power in regard to future injury has led some practitioners to question the use of TL monitoring. However, it is important to understand that the ability of single variables to predict injuries will be limited considering the multitude of factors that may influence injury risk, including genetics [17], previous injury history [18], psycho-social stress [19-21], different psychological coping strategies [22], and even coaching style [23]. Additionally, the use of inconsistent injury reporting methods (e.g., "medical attention injuries" versus "match time loss only") and the small number of injuries typically seen in many studies makes it difficult to compare results between studies $[6$, 24]. One solution to this issue is to adopt a universal injury categorization tool like the Subsequent Injury Classification Model 2.0 [25]. Similar to TL-I, there are limitations in the ability of single metrics to estimate performance with precision. Many factors including nutritional status [26], percentage of training affected by injury $[27,28]$, and coaching style $[29,30]$ affect training adaptations and subsequent performance. Notwithstanding these limitations, TL monitoring is still considered an important part of the athlete monitoring process $[1,3]$. To improve this process, a multi-factorial approach that considers an athlete's daily readiness to train and informal variables like sports coaches' experience and understanding of athletes is recommended to enhance the understanding of TL-I and TL-P [31, 32].

In light of our improved understanding of the impact psychosocial/cognitive factors have on performance and injury, recent examinations of periodization theory and advances in using subjective TL measures, the purpose of this commentary is to provide a practical perspective on the current state of subjective training load (TL) monitoring for performance enhancement and injury prevention. It would also seem timely to reevaluate the importance and weighting of subjective TL measures. Common limitations associated with subjective TL monitoring will also be addressed as well as possible evidence-informed solutions to these issues. Further, a critical examination of common methods of calculation used in TL monitoring models is also warranted.

\section{The Impact of Psychosocial Factors on Injury and Performance}

Despite appearing to be important moderators of TL-I and TL-P [19, 20, 33, 34], non-physical mental factors like mental fatigue, effort, stress, and motivation have received comparatively little attention to physical factors. Mental fatigue is a psychobiological state caused by demanding cognitive activity relative to the mental effort and motivation required to perform a task [34, 35]. Mental fatigue can be considered a component of mental stress, which may manifest in different forms including varied maladaptive coping behaviors (e.g., self-blame) and low perceived motivation [21, 36].

It is notable that mental factors and mental load seem to differ between open and closed skill sports. Open 
skill sports (e.g., basketball, table tennis) require players to react in an unpredictable and changing externally paced environment while closed skill sports are performed in an environment that is relatively predictable, consistent, and internally paced (e.g., shot put, swimming) [37]. Due to these differences, open and closed skill sports place very different mental demands on athletes, and these demands develop different mental qualities [38-42]. For instance, athletes in open skill sports may develop better visual attention, action execution, and decision-making skills compared to closed skill sports athletes [40-42]. It is logical to suggest that the mental fatigue/stress from sports demands may moderate both TL-I and TL-P [21, 34]. Hypothetically, open skill sports may have greater incidences of injury at the same ACWRs and may possess a very different optimal TL-P relationship (i.e., require a longer taper to allow for extra mental load to dissipate) when compared to closed skill sports. This theorised relationship is detailed in Fig. 1.

\section{Updates to Periodization Theory}

Coinciding with our increased knowledge of the impact non-physical factors have on performance and injury, it is interesting to note theories underpinning training periodization have recently been questioned [32, 43]. Modeling performance and injury is an associated extension of periodization theory [43]. A major assumption and limitation related to current TL models is that mechanical training stress or external TL is an independent signal for "fitness"/"fatigue" adaptations. However, an independent signal model does not accurately reflect training environments where multiple stressors (e.g., mechanical, emotional, nutritional) impact athletic adaptations and performance [26, 29,33], nor does it reflect recent consensus definitions of TL [3], advances in the general adaptation syndrome model that consider non-mechanical training stress [43] and more contemporary allostatic and cognitive appraisal stress theories [21, 32, 44]. These contemporary stress theories suggest there is a complex and collaborative emotional, physiological, immunological, and psychological response driven by the brain's perceptions of stressors [32, 44].

The allostatic stress and cognitive appraisal paradigms may aid our understanding in effectively evaluating TL measures. Subjective assessments like sRPE may

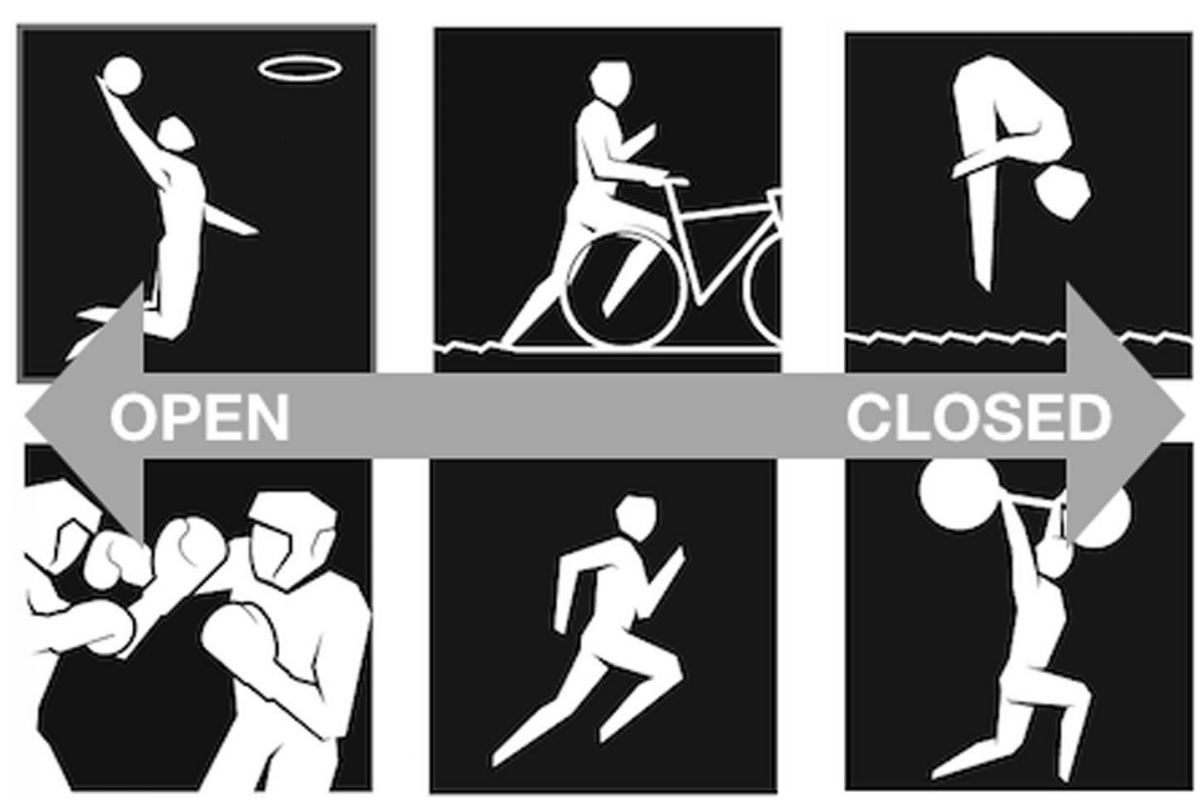

AT SAME CTL-ATL OR ACWR

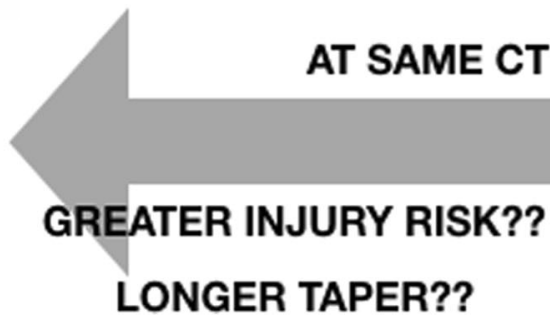

\section{LESSER INJURY RISK?? SHORTER TAPER??}

Fig. 1 Possible interaction effects of open and closed skill sports on training load variables, performance, and injury risk. Individual London 2012 Olympic pictograms reproduced in complete figure with permission from the International Olympic Committee. CTL, chronic training load; ATL, acute training load; ACWR, acute to chronic workload ratio 
reflect both the allostatic stress and the cognitive appraisal of the stress as it theoretically encompasses both the mechanical stress applied and also the (conscious) perception of that stress [32]. Compared to objective measures, sRPE may be able to better account for the allostatic stress athlete experience in mixed training sessions (e.g., tactical, skill, strength, fitness) [45, 46] and the mental load (e.g., learning a new skill or tactical strategy, competing against an unfamiliar opponent) during these sessions $[47,48]$. However, it is currently unknown exactly how mental load affects sRPE, particularly in team-based open skill sports.

Although subjective measures may have advantages as stand-alone measures, practitioners should not discount established valid objective measures when monitoring TL. It is accepted that internal and external TL measures should be used or compared with multiple variables to better understand TL-I and TL-P [31]. It is also suggested that both subjective and objective internal TL measures should be viewed as interrelated but different constructs [31]. For instance, previous studies have reported $\sim 50 \%$ unexplained variance between objective heart rate (HR)-derived measures and sRPE measures [31]. This highlights that both objective and subjective TL measures are not interchangeable and can give very different information. As such, if subjective measures provide a better illustration of "allostatic" load, the weighting of and comparisons between $\mathrm{TL}$ variables may need to be reconsidered for best practice. Currently, it is common in sports science to compare subjective perceptional measures (sRPE) to both objective internal (e.g., HR) and external (e.g., GPS-derived running measures) TL measures for validity purposes $[45,49]$. However, a paradigm shift may be warranted whereby objective measures are compared to the subjective as the criterion to determine construct validity [50]. In regard to determining which TL measures to implement for practitioners, the authors suggest sRPE would seem to be a logical first choice due to the aforementioned reasons and low cost [1]. However, TL measures should be chosen on a case-by-case basis depending on the nature of the sport (e.g., professional road cycling may choose sRPE as a secondary measure behind power output and HR response) and characteristics of training environment (e.g., logistics, budget). It also bears repeating practitioners should not expect to be able to use one sole variable to fully explain internal or external TL, e.g., sRPE will not fully explain HR response to training.

It has been also suggested that a further step to qualify sRPE as a useful TL measure is to compare it against the changes in injury rates or performance to [31]. This practice may be misleading at present when considering the lack of consensus injury classifications $[24,25]$ and the difficulty sports science has in adequately defining performance (especially in open skill team sports) [51, 52]. Despite the inconsistencies in injury classification in prior research, subjective TL monitoring with sRPE seems associated with injury risk [16]. However, as mentioned prior, it is currently a poor predictor of future injury as a sole variable [16]. In regard to the difficulties in defining performance, the authors feel it is important to differentiate prior research examining subjective TL monitoring with performance in physical tests (e.g., a countermovement jump) compared to performance in actual sports competition as these may very well be unrelated [52].

When examining the performance outcomes in competition, there is very little research in this area, but there does appear to be some relationship with subjective TL monitoring and performance in both open [46, $53,54]$ and closed skill $[49,55,56]$ sports. However, as lower injury rates are significantly associated with competitive success in both open and closed skill sports $[27,57]$, this relationship with performance outcomes may simply be due to lower injury rates and not any boost in performance per se [27]. For instance, effectively applying subjective TL monitoring may lead to a reduced injury rate through better management of injury risk, which in turn would likely improve performance. Whether this distinction is meaningful to practitioners is another question altogether as increased performance is desired in most cases, regardless of means. However, at the moment, the level of evidence to support the effectiveness of using subjective measures in similar "fitness"/ "fatigue" models like the ACWR to monitor and manipulate training for performance purposes is not yet well established [52].

\section{Subjective Training Load Monitoring: Limitations and Possible Solutions}

Limitations of using sRPE to monitor TL and their possible solutions should also be acknowledged [58]. The first potential limitation of using sRPE relates to the purpose for using TL monitoring. Although sRPE may give a better representation of overall load on the athlete, it should not be interpreted as a representation of physiological or biomechanical load. If physiological or biomechanical load are of paramount importance to sports' training practices (e.g., heart rate and power output in professional road cycling), sRPE may be of less relevance. Other limitations include practical errors common in recording sRPE. These include using non-validated sRPE scales (e.g., linear scales or scales without verbal anchors) and failing to obtain individual responses (e.g., peer presence on the rating of sRPE). Anecdotally, poor education of athletes as to the importance of giving accurate responses and how SRPE 
will be used by practitioners is commonly reported. If education around SRPE is not adequate, athletes may answer dishonestly in an attempt to manipulate future training sessions or team selection. Using a global sRPE score with the common 10-point category ratio scale (CR10) may also reduce the measure's sensitivity to account for the range of biomechanical and physiological exertion demands across training [7] and fail to distinguish between psychophysiological responses to training stress [48]. To counter these issues, it is recommended that practitioners follow the fundamental rules of psychometrics in administering sRPE or any subjective measure [11]. To improve sensitivity, a 100-point RPE category ratio scale (CR100) should be considered due to more verbal anchors and a finer grading compared to the CR10 scale [59-61]. To examine different components of training stress, practitioners may also consider differential RPE. Differential RPE refines how athletes rate different components of training/performance and requires separate scores for combinations of breathlessness (bRPE), leg muscle exertion (lRPE), upper body exertion (uRPE), and technical/cognitive exertion (tRPE) and in some cases match exertion (mRPE) [47, 48, 62]. With these components, differential RPE seems to encompass perceptions of separate physiological (bRPE) and biomechanical load (IRPE) [63] while also accounting for mental load (tRPE). As an example, tRPE in isolation appears sensitive to the quality of opposition in English Premier League soccer [47]. Differential RPE may also enhance measurement precision and sensitivity and improve within-athlete reliability compared to traditional global sRPE scores [62, 64]. Practically, separate scores (e.g., bRPE, IRPE, tRPE) may be averaged to give a global RPE score if desired [47]. However, practitioners will need to weigh these potential benefits against the increased number of measures and reporting requirements with differential RPE. These increased requirements are a potential practical limitation and may affect athlete compliance. Figure 2 provides an example of how sRPE or differential RPE may be combined with other well-known measures to create a multivariate TL model that considers physiological, biomechanical, and mental load [63].

\section{Training Load Model Calculation Methods}

There are also limitations in how various TL metrics, like the ACWR, are calculated. Specifically, there has been a debate over the arbitrary length of acute and chronic periods and deciding what training components should be included in the models $[46,65,66]$. Additionally, there has also been criticism over appropriate calculation methods. Rolling averages (which is the most common method used to calculate the 7- and 28-day periods of the ACWR) may not account for variations in the way TL is accumulated and the decaying nature of "fitness" and "fatigue" [1, 67, 68]. As such, it has been suggested that exponentially weighted moving averages (EWMA) may be a superior alternative [67-69]. However, there are also conceptual issues with EWMA and other TL models when considering athletes will likely have individual decay rates of both "fitness" and "fatigue." For instance, a recent study on rugby sevens players used the Bannister impulse response model to predict heart rate variability (as a substitute for performance measures) from sRPE [70]. The mean "fitness" and "fatigue" decay rates for sRPE were $20 \pm 14$ and $11 \pm 7$ days respectively [70]. Despite the method of determining "fitness" and "fatigue" decay rates being questionable, the arbitrary 7 - and 28-day acute and chronic period lengths commonly used to determine the ACWR may not be appropriate for all sports or

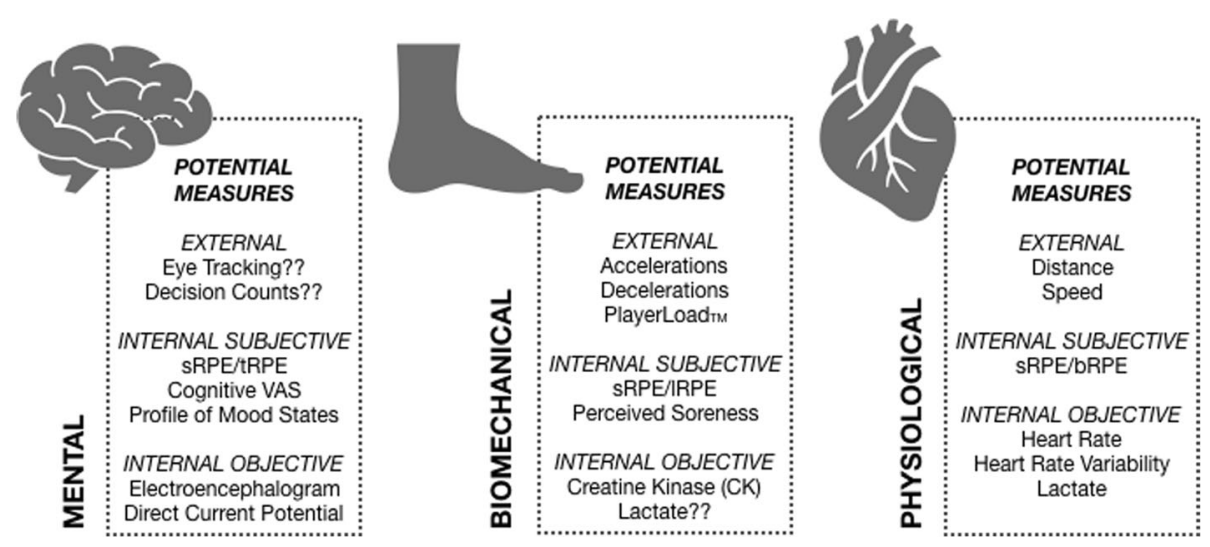

Fig. 2 Potential measures to combine with differential RPE or SRPE in a multivariate training load model that considers physiological, biomechanical, and mental load. Adapted from Vanrenterghem et al. [63]. sRPE, sessional rating of perceived exertion; tRPE, technical rating of perceived exertion; IRPE, leg muscle rating of perceived exertion; bRPE, breathe rating of perceived exertion (breathlessness); VAS, visual analogue scale 
individuals $[2,65]$. Using different period lengths would seem relevant to athletes adapted to different microand mesocycle lengths (e.g., microcycles 3-10 days, mesocycles 2-6 weeks) or who are within uncommon training periods (e.g., competition periods or returning from injury). Examinations of different acute and chronic time frames have resulted in varied relationships with injury risk $[2,65]$. For example, 3 - or 6-day acute and 21-day chronic periods best explained injury risk in one investigation involving Australian football players [65]. However, when accounting for the interaction of absolute chronic TL levels with injury risk, another investigation in the same sport found no improved predictive capacity above the common 7 - and 28-day periods compared with combinations in acute periods of 7 and 14 days and chronic periods of 21, 28, 35, 42, 49, and 56 days [2]. From this research, practitioners may be able to adjust the length of acute and chronic periods in the ACWR based on the lengths of their preferred training micro- and mesocycles [2]. However, as mentioned, it is also worth considering acute and chronic periods may be both individual and idiosyncratic to different sports and may require calibration to an objective measure [5]. Further consideration of which training components (e.g., technical, resistance, recovery) should be included in TL models for association or prediction purposes is also warranted. A recent study on Australian football players suggested a model using only skill training sRPE is better for predicting performance than a model using total sRPE [46]. Hence, a possible advancement may be to record separate technical and non-technical training sRPE scores and differentiate between each in analyses. However, the level of evidence for idiosyncratic acute and chronic periods and distinguishing between technical and non-technical training sRPE in TL models is not yet well developed.

\section{"Acute" and "Chronic" Decision-Making Tools}

Additional limitations with TL monitoring using training impulse (e.g., the ACWR) is that they are predominately "chronic" decision-making tools (e.g., how to structure training from week to week). They also rely upon post-training analysis. It should be noted that the ACWR can be calculated and compared daily in an attempt to assess athlete adaptations, e.g., an internal TL increase at the same external TL may signify maladaptation. However, this practice may not be sensitive enough to inform daily training modifications [71] which becomes problematic when "acute" decisions, like modifying training based on day-to-day athlete readiness, are required. Although dependent on context, it is the authors' experience that most high-level coaches (e.g., world record/multiple Olympic games and professional team sports coaches) prefer tools that aid in these "acute" decisions (i.e., "Do I need to make a change today? And if so, by how much?"). "Chronic" decision-making information may not be as highly valued by such coaches, and explanations of ACWR principles are typically well known when given in familiar language. This preference for "acute" tools may reflect an attempt by coaches not to become "trapped" in any non-opportunistic rigidity associated with long-term planning (a management theory principle) [72, 73], especially when athletes' needs/priorities may change daily. Examples of "acute" tools may include both subjective (e.g., perceived wellness scales [11]) and objective (e.g., heart rate variability [74]). It would then seem important for practitioners to quantify which "acute"/ "chronic" decision-making tools coaches feel can best aid their practice and implement them on a bespoke basis. The authors suggest athlete-monitoring tools can be divided into four categories: (i) "acute" subjective, (ii) "acute" objective, (iii) "chronic" subjective, and (iv) "chronic" objective. A list of possible "acute" and "chronic" decision-making tools for different types of sports (e.g., closed versus open) and how practitioners may combine them with sRPE/differential RPE are provided in Fig. 3 [3, 74]. Besides coach preference, the usefulness of these "acute" decision-making tools may vary from sport to sport. For instance, when compared to central nervous system measure like direct current potential, autonomic nervous system measures (e.g., heart rate variability) may not be very meaningful for explosive sports like weightlifting or track and field jumps and throws. Similar to TL measures, these measures should be recognized as providing different information, e.g., autonomic nervous system status may be practically unrelated to central nervous system status in an athlete. Further investigations of the utility of "acute" decision-making tools in different sports, their relationship with TL measures, and other informal variables like coach experience and intuition would seem warranted.

\section{Call to Action}

Currently, the level of evidence supporting the efficacy of TL monitoring systems, and in particular, the ACWR, is not high. As such, there are a number of considerations presented in this article practitioners should take into account when implementing TL monitoring in their practice. Based on these considerations, the authors put forward a call to action for further examinations of the key issues identified in this commentary that would be of use in an applied setting. These issues include quantifying the ability to assess mental load with current subjective measures, the contribution 


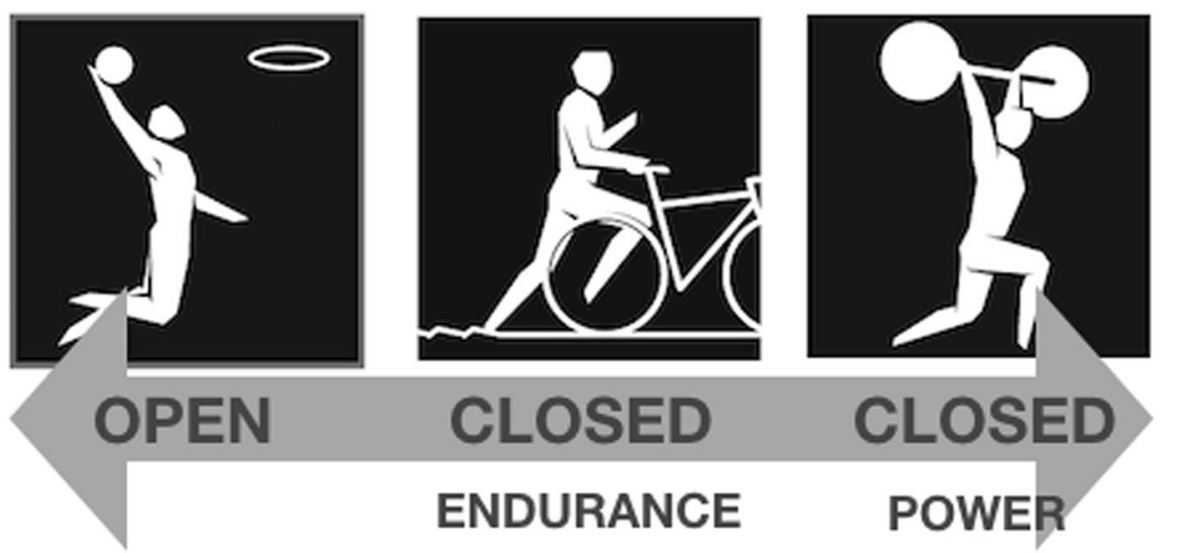

\begin{tabular}{|c|c|c|}
\hline $\begin{array}{l}\text { POTENTIAL } \\
\text { MEASURES }\end{array}$ & $\begin{array}{l}\text { POTENTIAL } \\
\text { MEASURES }\end{array}$ & $\begin{array}{l}\text { POTENTIAL } \\
\text { MEASURES }\end{array}$ \\
\hline $\begin{array}{c}\text { ACUTE SUBJECTIVE } \\
\text { POMS/ARSS } \\
\text { Subjective Wellness } \\
\text { MSK Screen }\end{array}$ & $\begin{array}{c}\text { ACUTE SUBJECTIVE } \\
\text { POMS/ARSS } \\
\text { Subjective Wellness } \\
\text { MSK Screen }\end{array}$ & $\begin{array}{c}\text { ACUTE SUBJECTIVE } \\
\text { POMS/ARSS } \\
\text { Subjective Wellness } \\
\text { MSK Screen }\end{array}$ \\
\hline $\begin{array}{l}\text { ACUTE OBJECTIVE } \\
\text { Heart Rate Variability } \\
\text { DC Potential } \\
\text { Jump Analysis } \\
\text { MSK Screen }\end{array}$ & $\begin{array}{c}\text { ACUTE OBJECTIVE } \\
\text { Heart Rate Variability } \\
\text { DC Potential } \\
\text { Blood Hormone Markers } \\
\text { MSK Screen }\end{array}$ & $\begin{array}{l}\text { ACUTE OBJECTIVE } \\
\text { DC Potential } \\
\text { Blood Hormone Markers } \\
\text { Jump Analysis } \\
\text { MSK Screen }\end{array}$ \\
\hline $\begin{array}{c}\text { CHRONIC SUBJECTIVE } \\
\text { SRPE / Differential RPE } \\
\text { TRIMP }\end{array}$ & $\begin{array}{c}\text { CHRONIC SUBJECTIVE } \\
\text { sRPE / Differential RPE } \\
\text { TRIMP }\end{array}$ & $\begin{array}{c}\text { CHRONIC SUBJECTIVE } \\
\text { sRPE / Differential RPE } \\
\text { TRIMP }\end{array}$ \\
\hline $\begin{array}{c}\text { CHRONIC OBJECTIVE } \\
\text { Accelerometer / GPS } \\
\text { TRIMP } \\
\text { Heart Rate TRIMP }\end{array}$ & $\begin{array}{c}\text { CHRONIC OBJECTIVE } \\
\text { Power Meter / GPS } \\
\text { TRIMP } \\
\text { Heart Rate TRIMP }\end{array}$ & $\begin{array}{c}\text { CHRONIC OBJECTIVE } \\
\text { System Mass TRIMP } \\
\text { Accelerometer / LPT } \\
\text { TRIMP?? }\end{array}$ \\
\hline
\end{tabular}

Fig. 3 A potential framework of "acute" and "chronic" decision-making tools for different types of sports. POMS, Profile of Mood States; ARSS, Acute Recovery and Stress Scale; MSK, musculoskeletal; DC, direct current; LPT, linear position transducer; GPS, Global Positioning System; RPE, rate of perceived exertion; TRIMP, training impulse. Individual London 2012 Olympic pictograms reproduced in complete figure with permission from the International Olympic Committee

of mental load to existing subjective measures and establishing if mental load differs between open and closed skill sports. From here, examinations into how the ability to handle mental load may moderate TL-I and TL-P relationships (similar to previous examinations on physical capabilities) would be of interest. The relationship between subjective measures, performance, and injury should also be further investigated in both open and closed skill sports. These further investigations should attempt to quantify competition performance outcomes independent of injury rates to determine if models like the ACWR are effective in modeling performance in of itself, i.e., distinct to benefits of improved training availability due to lower injury rate. They should also encompass which methods of TL model calculation (e.g., rolling averages and EWMA, different acute and chronic periods, varying "fitness"-"fatigue" decay rates) have stronger relationships with performance and injury. "Acute" decision-making tools should be also assessed against TL models and for their suitability in different sports under common practical conditions athletes face. Lastly, it seems important for practitioners to identify which methods of monitoring are most important to sports coaches in their practice and fit those into a bespoke multi-factorial model. 


\section{Abbreviations}

ACWR: Acute to chronic workload; bRPE: Ratings of breathlessness; CR10: 10point category ratio scale; CR100: 100-point category ratio scale; EWMA: Exponentially weighted moving averages; HR: Heart rate; IRPE: Ratings of leg muscle exertion; mRPE: Ratings of match exertion; SRPE: Sessional ratings of perceived exertion; TL: Training load; TL-I: Training load-injury relationship; TL-P: Training load-performance relationship; tRPE: Ratings of technical/cognitive exertion; URPE: Ratings of upper body exertion

\section{Acknowledgements}

The authors wish to thank the International Olympic Committee for their permission to use the London 2012 Olympic pictograms for the production of Figs. 1 and 3 .

\section{Funding}

There was no financial or material support.

\section{Availability of Data and Materials}

Not applicable

\section{Authors' Contribution}

JC drafted the initial concept, and all authors contributed to the drafting, critical revision, and approval of the final manuscript. All authors read and approved the final manuscript.

\section{Ethics Approval and Consent to Participate}

Not applicable

\section{Consent for Publication}

Not applicable

\section{Competing Interests}

The authors, Joseph Coyne, Gregory Haff, Aaron Coutts, Robert Newton, and Sophia Nimphius, declare that they have no competing interests.

\section{Publisher's Note}

Springer Nature remains neutral with regard to jurisdictional claims in published maps and institutional affiliations.

\section{Author details}

${ }^{1}$ Centre for Exercise and Sports Science, School of Medical and Health Sciences, Edith Cowan University, Joondalup, Western Australia, Australia. ${ }^{2}$ Human Performance Research Centre, Faculty of Health, University of Technology Sydney, Moore Park, New South Wales, Australia.

Received: 27 August 2018 Accepted: 30 November 2018 Published online: 20 December 2018

\section{References}

1. Bourdon PC, Cardinale M, Murray A, Gastin P, Kellmann M, Varley MC, et al. Monitoring athlete training loads: consensus statement. Int J Sports Physiol Perform. 2017;12(Suppl 2):161-70. https://doi.org/10.1123/ijspp.2017-0208.

2. Stares J, Dawson B, Peeling P, Heasman J, Rogalski B, Drew M, et al. Identifying high risk loading conditions for in-season injury in elite Australian football players. J Sci Med Sport. 2018;21(1):46-51 doi:https://doi. org/10.1016/j.jsams.2017.05.012

3. Soligard T, Schwellnus M, Alonso J-M, Bahr R, Clarsen B, Dijkstra HP, et al How much is too much? (part 1) International Olympic Committee consensus statement on load in sport and risk of injury. Br J Sports Med. 2016:50(17):1030-41. https://doi.org/10.1136/bjsports-2016-096581.

4. Impellizzeri FM, Rampinini E, Marcora SM. Physiological assessment of aerobic training in soccer. J Sports Sci. 2005;23(6):583-92. https://doi.org/10. 1080/02640410400021278.

5. Bannister EW, Calvert, T.W., Savage, M.V. and Bach, T.M. A systems model of training for athletic performance. Aust J Sports Med 1975(7):57-61.

6. Drew MK, Finch CF. The relationship between training load and injury, illness and soreness: a systematic and literature review. Sports Med. 2016; 46(6):861-83. https://doi.org/10.1007/s40279-015-0459-8.

7. MCLaren SJ, Macpherson TW, Coutts AJ, Hurst C, Spears IR, Weston M. The relationships between internal and external measures of training load and intensity in team sports: a meta-analysis. Sports Med. 2018;48(3):641-58. https://doi.org/10.1007/s40279-017-0830-z.

8. Saw AE, Main LC, Gastin PB. Monitoring the athlete training response: subjective self-reported measures trump commonly used objective measures: a systematic review. Br J Sports Med. 2016;50(5):281-91. https:// doi.org/10.1136/bjsports-2015-094758.

9. Smith MR, Fransen J, Coutts A. Inducing and assessing cognitive fatigue. Amsterdam: European College of Sport Science Annual Congress; 2014.

10. Burgess DJ. The research doesn't always apply: practical solutions to evidence-based training-load monitoring in elite team sports. Int J Sports Physiol Perform. 2017;12(Suppl 2):S2-136-S2-41. https://doi.org/10.1123/ ijspp.2016-0608.

11. Saw AE, Kellmann M, Main LC, Gastin PB. Athlete self-report measures in research and practice: considerations for the discerning reader and fastidious practitioner. Int J Sports Physiol Perform. 2017:12:S2-127 S2-35.

12. Gabbett TJ. The development and application of an injury prediction mode for noncontact, soft-tissue injuries in elite collision sport athletes. J Strength Con Res. 2010;24(10):2593-603. https://doi.org/10.1519/JSC Ob013e3181f19da4.

13. Gabbett TJ. The training-injury prevention paradox: should athletes be training smarter and harder? Br J Sports Med. 2016:50(5):273-80. https://doi. org/10.1136/bjsports-2015-095788.

14. Blanch P, Gabbett TJ. Has the athlete trained enough to return to play safely? The acute:chronic workload ratio permits clinicians to quantify a player's risk of subsequent injury. Br J Sports Med. 2015;50(8):471-5. https:// doi.org/10.1136/bjsports-2015-095445.

15. Ritchie D, Hopkins WG, Buchheit M, Cordy J, Bartlett JD. Quantification of training load during return to play after upper- and lower-body injury in Australian rules football. Int J Sports Physiol Perform. 2017;12(5):634-41. https://doi.org/10.1123/ijspp.2016-0300.

16. Fanchini M, Rampinini E, Riggio M, Coutts AJ, Pecci C, McCall A. Despite association, the acute:chronic work load ratio does not predict non-contact injury in elite footballers. Sci Med in Football. 2018:1-7. https://doi.org/10. 1080/24733938.2018.1429014.

17. Pickering C, Kiely J. ACTN3: more than just a gene for speed. Front Physiol. 2017:8:1080. https://doi.org/10.3389/fphys.2017.01080.

18. Fulton J, Wright K, Kelly M, Zebrosky B, Zanis M, Drvol C, et al. Injury risk is altered by previous injury: a systematic review of the literature and presentation of causative neuromuscular factors. Int J Sports Phys Ther. 2014;9(5):583-95.

19. Mann JB, Bryant K, Johnstone B, Ivey P, Sayers SP. The effect of physical and academic stress on illness and injury in division 1 college football players. J Strength Con Res. 2015;30(1):20-5. https://doi.org/10.1519/jsc. 0000000000001055

20. Timpka $T$, Jacobsson J, Bargoria $\mathrm{V}$, Périard JD, Racinais S, Ronsen O, et al. Preparticipation predictors for championship injury and illness: cohort study at the Beijing 2015 International Association Of Athletics Federations World Championships. Br J Sports Med. 2017;51(4):271-6. https://doi.org/10.1136/ bjsports-2016-096580.

21. Timpka T, Jacobsson J, Dahlström Ö, Kowalski J, Bargoria V, Ekberg J, et al. The psychological factor 'self-blame' predicts overuse injury among top-level Swedish track and field athletes: a 12-month cohort study. Br J Sports Med. 2015:49(22):1472-7. https://doi.org/10.1136/ bjsports-2015-094622.

22. Tranaeus U, Johnson U, Engstrom B, Skillgate E, Werner S. A psychological injury prevention group intervention in Swedish Floorball. Knee Surg Sports Traumatol Arthrosc. 2015;23(11):3414-20. https://doi.org/10.1007/s00167014-3133-z

23. Ekstrand J, Lundqvist D, Lagerbäck L, Vouillamoz M, Papadimitiou N, Karlsson J. Is there a correlation between coaches' leadership styles and injuries in elite football teams? A study of 36 elite teams in 17 countries. $\mathrm{Br}$ J Sports Med. 2018:52:527-31. https://doi.org/10.1136/bjsports-2017-098001.

24. Hulin BT. The never-ending search for the perfect acute:chronic workload ratio: what role injury definition? Br J Sports Med. 2017:51(13):991-2. https:// doi.org/10.1136/bjsports-2016-097279.

25. Toohey LA, Drew MK, Fortington LV, Finch CF, Cook JL. An updated subsequent injury categorisation model (SIC-2.0): data-driven categorisation of subsequent injuries in sport. Sports Med. 2018. https://doi.org/10.1007/ s40279-018-0879-3.

26. Jeukendrup AE. Periodized nutrition for athletes. Sports Med (Auckland, Nz) 2017;47(Suppl 1):51-63. https://doi.org/10.1007/s40279-017-0694-2. 
27. Drew MK, Raysmith BP, Charlton PC. Injuries impair the chance of successful performance by sportspeople: a systematic review. Br J Sports Med. 2017; 51(16):1209-14. https://doi.org/10.1136/bjsports-2016-096731.

28. Raysmith BP, Drew MK. Performance success or failure is influenced by weeks lost to injury and illness in elite Australian track and field athletes: a 5-year prospective study. J Sci Med Sport. 2016;19(10):778-83. https://doi. org/10.1016/j.jsams.2015.12.515.

29. Carleton EL, Barling J, Christie AM, Trivisonno M, Tulloch K, Beauchamp MR. Scarred for the rest of my career? Career-long effects of abusive leadership on professional athlete aggression and task performance. J Sport Exerc Psychol. 2016;38(4):409-22. https://doi.org/10.1123/jsep.2015-0333.

30. Davis L, Appleby R, Davis P, Wetherell M, Gustafsson H. The role of coachathlete relationship quality in team sport athletes' psychophysiological exhaustion: implications for physical and cognitive performance. J Sports Sci. 2018:1-8. https://doi.org/10.1080/02640414.2018.1429176.

31. Weaving $D$, Jones $B$, Till $K$, Abt G, Beggs $C$. The case for adopting a multivariate approach to optimize training load quantification in team sports. Front Physiol. 2017;8:1024. https://doi.org/10.3389/fphys.2017.01024.

32. Kiely J. Periodization theory: confronting an inconvenient truth. Sports Med. 2018;48(4):753-64. https://doi.org/10.1007/s40279-017-0823-y.

33. Le Mansec Y, Pageaux B, Nordez A, Dorel S, Jubeau M. Mental fatique alters the speed and the accuracy of the ball in table tennis. J Sports Sci. 2017:19. https://doi.org/10.1080/02640414.2017.1418647.

34. Smith MR, Coutts AJ, Merlini M, Deprez D, Lenoir M, Marcora SM. Mental fatigue impairs soccer-specific physical and technical performance. Med Sci Sports Exerc. 2016;48(2):267-76. https://doi.org/10.1249/mss. 0000000000000762.

35. Marcora SM, Staiano W, Manning V. Mental fatigue impairs physical performance in humans. J Appl Physiol. 2009;106(3):857-64. https://doi.org/ 10.1152/japplphysiol.91324.2008.

36. Stults-Kolehmainen MA, Bartholomew JB, Sinha R. Chronic psychological stress impairs recovery of muscular function and somatic sensations over a 96-hour period. J Strength Con Res. 2014;28(7):2007-17. https://doi.org/10. 1519/jsc.0000000000000335.

37. Di Russo F, Bultrini A, Brunelli S, Delussu AS, Polidori L, Taddei F, et al. Benefits of sports participation for executive function in disabled athletes. J Neurotrauma. 2010;27(12):2309-19. https://doi.org/10.1089/neu.2010.1501.

38. Wang $\mathrm{C}-\mathrm{H}$, Chang $\mathrm{C}-\mathrm{C}$, Liang $\mathrm{Y}-\mathrm{M}$, Shih $\mathrm{C}-\mathrm{M}$, Chiu W-S, Tseng $\mathrm{P}$, et al. Open vs. closed skill sports and the modulation of inhibitory control. PLoS One. 2013;8(2):e55773. https://doi.org/10.1371/journal.pone.0055773.

39. Mann DT, Williams AM, Ward P, Janelle CM. Perceptual-cognitive expertise in sport: a meta-analysis. J Sport Exerc Psychol. 2007;29(4):457-78.

40. Yarrow K, Brown P, Krakauer JW. Inside the brain of an elite athlete: the neural processes that support high achievement in sports. Nat Rev Neurosci. 2009;10(8):585-96. https://doi.org/10.1038/nrn2672.

41. Nakata H, Yoshie M, Miura A, Kudo K. Characteristics of the athletes' brain: evidence from neurophysiology and neuroimaging. Brain Res Rev. 2010; 62(2):197-211. https://doi.org/10.1016/j.brainresrev.2009.11.006.

42. Overney LS, Blanke O, Herzog MH. Enhanced temporal but not attentional processing in expert tennis players. PLoS One. 2008;3(6):e2380. https://doi. org/10.1371/journal.pone.0002380.

43. Cunanan AJ, DeWeese BH, Wagle JP, Carroll KM, Sausaman R, Hornsby WG, et al. The general adaptation syndrome: a foundation for the concept of periodization. Sports Med. 2018;48(4):787-97. https://doi.org/10.1007/ s40279-017-0855-3.

44. Wilson TD, Gilbert DT. Explaining away: a model of affective adaptation. Perspect Psychol Sci. 2008;3(5):370-86. https://doi.org/10.1111/j.1745-6924. 2008.00085.x.

45. Delaney JA, Duthie GM, Thornton HR, Pyne DB. Quantifying the relationship between internal and external work in team sports: development of a novel training efficiency index. Sci Med Football. 2018:1-8. https://doi.org/10.1080/ 24733938.2018.1432885.

46. Graham SR, Cormack S, Parfitt G, Eston R. Relationships between model predicted and actual match performance in professional Australian footballers during an in-season training macrocycle. Int J Sports Physiol Perform. 2017:1-25. https://doi.org/10.1123/ijspp.2017-0026.

47. Barrett S, McLaren S, Spears I, Ward P, Weston M. The influence of playing position and contextual factors on soccer players' match differential ratings of perceived exertion: a preliminary investigation. Sports. 2018;6(1):13.

48. Weston M, Siegler J, Bahnert A, McBrien J, Lovell R. The application of differential ratings of perceived exertion to Australian football league matches. J Sci Med Sport. 2015;18(6):704-8. https://doi.org/10.1016/j.jsams. 2014.09.001.

49. Wallace LK, Slattery KM, Coutts AJ. A comparison of methods for quantifying training load: relationships between modelled and actual training responses. Eur J Appl Physiol. 2014;114(1):11-20. https://doi.org/10.1007/ s00421-013-2745-1.

50. Jaspers A, Beéck TOD, Brink MS, Frencken WGP, Staes F, Davis JJ, et al. Relationships between the external and internal training load in professional soccer: what can we learn from machine learning? Int I Sports Physiol Perform. 2018;13(5):625-30. https://doi.org/10.1123/ijspp.2017-0299.

51. Sullivan C, Bilsborough JC, Cianciosi M, Hocking J, Cordy JT, Coutts AJ. Factors affecting match performance in professional Australian football. Int J Sports Physiol Perform. 2014;9(3):561-6. https://doi.org/10.1123/ijspp.2013-0183.

52. Fox JL, Stanton R, Sargent C, Wintour S-A, Scanlan AT. The association between training load and performance in team sports: a systematic review. Sports Med. 2018;48(12):2743-74. https://doi.org/10.1007/s40279-018-0982-5.

53. Aughey RJ, Elias GP, Esmaeili A, Lazarus B, Stewart AM. Does the recent internal load and strain on players affect match outcome in elite Australian football? J Sci Med Sport. 2016;19(2):182-6. https://doi.org/10.1016/j.jsams. 2015.02.005

54. McCaskie CJ, Young WB, Fahrner BB, Sim M. Association between preseason training and performance in elite Australian football. Int J Sports Physiol Perform. 0(0):1-25. https://doi.org/10.1123/ijspp.2018-0076.

55. Crowcroft S, McCleave E, Slattery K, Coutts AJ. Assessing the measurement sensitivity and diagnostic characteristics of athlete monitoring tools in national swimmers. Int J Sports Physiol Perform. 2016:1-21. https://doi.org/ 10.1123/ijspp.2016-0406.

56. Wood RE, Hayter S, Rowbottom D, Stewart I. Applying a mathematical model to training adaptation in a distance runner. Eur J Appl Physiol. 2005; 94(3):310-6. https://doi.org/10.1007/s00421-005-1319-2.

57. Hagglund M, Walden M, Magnusson H, Kristenson K, Bengtsson H, Ekstrand J. Injuries affect team performance negatively in professional football: an 11 year follow-up of the UEFA champions league injury study. Br J Sports Med. 2013:47(12):738-42. https://doi.org/10.1136/bjsports-2013-092215.

58. Haddad M, Stylianides G, Djaoui L, Dellal A, Chamari K. Session-RPE method for training load monitoring: validity, ecological usefulness, and influencing factors. Frontiers in Neuroscience. 2017;11:612. https://doi.org/10.3389/fnins.2017.00612.

59. Fanchini M, Ferraresi I, Modena R, Schena F, Coutts AJ, Impellizzeri FM. Use of CR100 scale for session rating of perceived exertion in soccer and its interchangeability with the CR10. Int J Sports Physiol Perform. 2016;11(3): 388-92. https://doi.org/10.1123/ijspp.2015-0273.

60. Scott TJ, Black CR, Quinn J, Coutts AJ. Validity and reliability of the sessionRPE method for quantifying training in Australian football: a comparison of the CR10 and CR100 scales. J Strength Con Res. 2013;27(1):270-6. https:// doi.org/10.1519/JSC.0b013e3182541d2e.

61. Borg E, Borg G. A comparison of AME and CR100 for scaling perceived exertion. Acta Psychol. 2002;109(2):157-75.

62. McLaren SJ, Smith A, Spears IR, Weston M. A detailed quantification of differential ratings of perceived exertion during team-sport training. J Sci Med Sport. 2017;20(3):290-5 doi:https://doi.org/10.1016/j.jsams.2016.06.011.

63. Vanrenterghem J, Nedergaard NJ, Robinson MA, Drust B. Training load monitoring in team sports: a novel framework separating physiological and biomechanical load-adaptation pathways. Sports Med. 2017;47(11):2135-42. https://doi.org/10.1007/s40279-017-0714-2.

64. McLaren SJ, Graham M, Spears IR, Weston M. The sensitivity of differential ratings of perceived exertion as measures of internal load. Int J Sports Physiol Perform. 2016;11(3):404-6.

65. Carey DL, Blanch P, Ong K-L, Crossley KM, Crow J, Morris ME. Training loads and injury risk in Australian football—differing acute: chronic workload ratios influence match injury risk. Br J Sports Med. 2016;51(16):1215-20. https://doi.org/10.1136/bjsports-2016-096309.

66. Lolli L, Batterham AM, Hawkins R, Kelly DM, Strudwick AJ, Thorpe R, et al. Mathematical coupling causes spurious correlation within the conventional acute-to-chronic workload ratio calculations. Br J Sports Med. 2017. https:// doi.org/10.1136/bjsports-2017-098110.

67. Menaspà $P$. Are rolling averages a good way to assess training load for injury prevention? Br J Sports Med. 2017;51(7):618-9. https://doi.org/10. 1136/bjsports-2016-096131.

68. Williams S, West $\mathrm{S}$, Cross MJ, Stokes KA. Better way to determine the acute: chronic workload ratio? Br J Sports Med. 2016;51(3):209. https://doi.org/10. 1136/bjsports-2016-096589. 
69. Murray NB, Gabbett TJ, Townshend AD, Blanch P. Calculating acute:chronic workload ratios using exponentially weighted moving averages provides a more sensitive indicator of injury likelihood than rolling averages. $\mathrm{Br} J$ Sports Med. 2016;51 (9):749. https://doi.org/10.1136/bjsports-2016-097152.

70. Williams S, West S, Howells D, Kemp SPT, Flatt AA, Stokes K. Modelling the HRV response to training loads in elite rugby sevens players. J Sports Sci Med. 2018;17(3):402-8.

71. Delaney JA, McKay BA, Thornton HR, Murray A, Duthie GM. Training efficiency and athlete wellness in collegiate female soccer. Sports Perform Sci Rep. 2018;1(19):1-3.

72. Coleman J. The best strategic leaders balance agility and consistency. Harvard Business Review; 2017.

73. Isenberg D. The tactics of strategic opportunism. Harvard Business Review; 1987.

74. Thorpe RT, Atkinson G, Drust B, Gregson W. Monitoring fatique status in elite team sport athletes: implications for practice. Int I Sports Physiol Perform. 2017:1-25. https://doi.org/10.1123/ijspp.2016-0434.

\section{Submit your manuscript to a SpringerOpen ${ }^{\circ}$ journal and benefit from:}

- Convenient online submission

- Rigorous peer review

- Open access: articles freely available online

- High visibility within the field

- Retaining the copyright to your article

Submit your next manuscript at $\boldsymbol{\nabla}$ springeropen.com 